\title{
Path Finder Surveillance
}

\author{
Komal Gaikwad, Pooja Jadhav, Priyanka Jyotik, Prof. Deepali Yewale \\ Department of E\&TC,AISSMS's IOIT Pune, India
}

\begin{abstract}
This is the world of wireless technology. This article describes an intelligent path finder system which is composed of microcontroller AT-Mega16, GSM modules which use RS232 standard and RF media for data transfer.,SD Card.. The hardware and software used in this system were characterized proto-type has been built to overcome many of the traditional information and navigation tools available to visitors. The system has shown a good performance in searching desired location in crowded area, especially In this article we present an evaluation of proto-type, focusing on the security and flexibility of visitor's experience when using the system.
\end{abstract}

Keywords: GSM module,,microcontroller AT-Mega16,RFID reader, SD Card.

\section{INTRODUCTION}

Path Finder Surveillance system is a kind of special Equipment which is used to guide the visitor in different places. It can display desired location as well as announce location to the user. Path Finder Surveillance can be used by any person without his/her education back ground. Provides security in the area by tracking location of the roaming visitor in premises.

The Visitor can be wondering around to find desired location and When no one can give proper guidance for that or misguided by some person by wrong information in such places whether it small premises or big premises path finder surveillance is the best option to guide visitor for that premises. It will save visitors time. One of the key requirements for the system developed was the need to provide sufficient flexibility to enable visitors to explore. Especially a number of visitors may choose their sources and destination where they want to reach. The system developed can convey the information presented. In addition, the system can effectively distribute human resource. The path finder surveillance system is a people-oriented service means and also one of the symbols of modernization.

\section{RELATED WORK}

Now we shall see the related work regarding the Path Finder Surveillance:

A]GSM-SMS Based control system for visitor

This paper represents GSM-SMS based control .It was based on PC based database system connected with Base station.Base station is developed by using microcontroller,GSM Module,Audio decoder.This system provides security in the area by tracking location of the roaming visitor in the premises.GSM provides compatibility with Integrated Digital Services Network.

B]How does RF communication system work?

Imagine an RF transmitter wiggling an electron in one location. This wiggling electron causes a ripple effect, somewhat akin to dropping a pebble in a pond. The effect is an electromagnetic (EM) wave that travels out from the initial location resulting in electrons wiggling in remote locations. An RF receiver can detect this remote electron wiggling. The RF communication system then utilizes this phenomenon by wiggling electrons in a specific pattern to represent information. The receiver can make this same information available at a remote location; communicating with no wires. This communication is limited to range and data rate.

\section{INDENTATIONS}

The path finder surveillance premises RFID tags will be attached according to their specified distances. As user enters in premises handheld machine is provided to them. User needs to enter his source and destination location with the help of keypad.Keypad is interfaced with microcontroller. Then visitor needs to show his RFID reader to the nearby RFID tags as the reader reads the RFID tags then next location will be display on LCD on hand held machine.At the same time audio message will be given to the user every time. In such way process repeats. But if any case user get confused or any annoying user try to misdirect the admin for any bad purpose then message will be displayed to the user that he is in wrong way same time using GSM modem message for that user will be given to the admin and so nearby security will reach at that visitor. Using GSM we are able to trace path of visitor. 


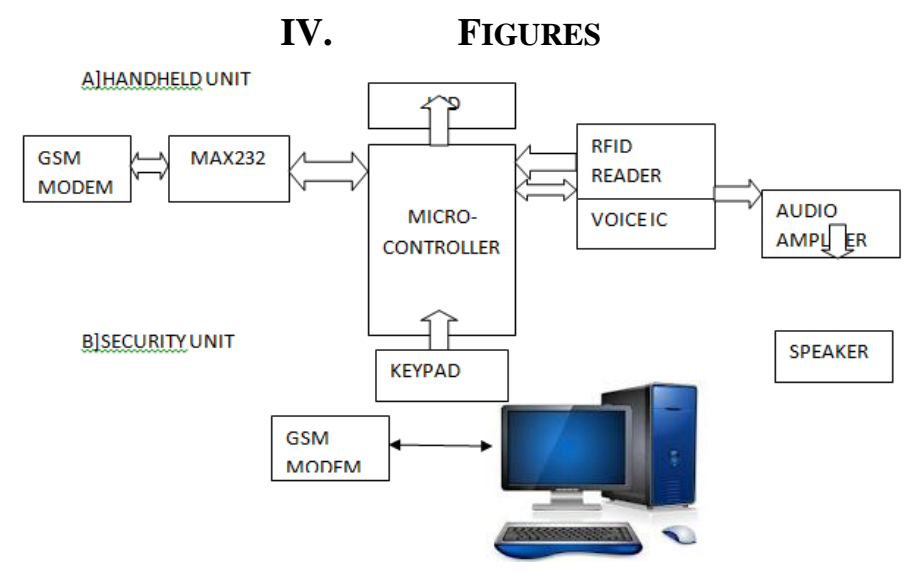

FIG. System Architecture Of Path Finder Surveillance

\section{Conclusion}

This paper provides one way of guiding visitor in big premises especially at secured places because this project is limited to manufacture such number of handheld machine and as few visitors for secure places ,so few handheld machines can be made efficiently. This paper will help visitor to reach destination early without any misguide.

\section{REFERENCES}

[1] K.Cheverst,N.Davies,K.Mitchell,A,Friday,and C.Efstratiou,'Developing a Context-aware Electronic Tourist Guide:Some Issues and Experience".Sci.Res.Ess.,Vol.5,No.8,pp.714-720,Apr.2010

[2] H.L.Chan,P.K.Chao,Y.C.Chen,and W.J.Kao,"Wireless Body Area Network for Physical -Activity classification and Fall Detection “.Med.Dev Biosens.,pp.157-160,Dec.2008

[3] Z.P.Liu,and G.L.Zhao,"Short -range wireless data transmission based on Nrf24L01".Appl.Sci.Technol.,Vol.35,No.3,pp.5558,Mar.2008.

[4] C.W.Liu,J.L.Zhao, and W.D.Yi.’Design of wireless image sensor node based on Nrf24101",Electrons Meas.Technol.,vol.6,No.31,pp.136,jun.2008.

[5] NordicSemiconductor,nRF240L01 productspecification.http://www.nordicsemi.com/index.cfm?obj=product\&act=display\&pro=89

[6] http://www.atmel.com/

[7] http://www.electricstuff.co.uk

[8] www.nippon.com 